\title{
Functional regulatory spaces and policy diffusion in Europe: The case of mountains
}

\author{
Jörg Balsiger ${ }^{a, b, *}$, Stéphane Nahrath ${ }^{c}$ \\ a Department of Geography and Environment, University of Geneva, Uni Mail, 40 Boulevard du Pont-d'Arve, \\ 1211 Geneva, Switzerland \\ b Institute for Environmental Sciences, University of Geneva, Uni Rondeau, 7 Route de Drize, 1227 Carouge, \\ Switzerland \\ ' Swiss Graduate School of Public Administration, University of Lausanne, Quartier UNIL-Mouline, 1015 Lausanne, \\ Switzerland
}

\section{A R T I C L E I N F O}

Article history:

Available online 30 January 2015

Keywords:

Functional regulatory space

Policy diffusion

Regional governance

Mountains

Europe

Alps

Pyrenees

Jura

Carpathians

Balkan Mountains

Dinaric Arc

Caucasus

\begin{abstract}
A B S T R A C T
The aim of this article is to propose a new analytical framework for comparing and explaining the emergence and diffusion of European regional mountain initiatives (ERMIs), envisaged as 'functional regulatory spaces' (FRS). The article examines three exploratory hypotheses. The first hypothesis considers that the different ERMIs (Alps, Pyrenees, Jura, Carpathian, Balkan Mountains, Dinaric Arc, Caucasus) can be compared, distinguished, and classified using the FRS approach. The second hypothesis addresses the relationship between the degree to which ERMIs correspond to an ideal-type FRS and their role and position within policy diffusion processes. We suggest that the more an ERMI corresponds to an ideal-type FRS, the more important is its role in diffusion processes. The third hypothesis focuses on the relationship between the degree of formalization and institutionalization of ERMIs and their role in policy diffusion processes. We argue that the more and the earlier an ERMI is "formalized" and "institutionalized" in a clear and robust way as a "mature" FRS, the more important its role, and the more central its position, in diffusion processes. This article is a very first attempt to link FRS and policy diffusion concepts. As such it seeks to assess the link's feasibility and relevance, rather than a definitive empirical (in)validation of the three hypotheses.
\end{abstract}

C) 2015 Elsevier Ltd. All rights reserved.

\section{Introduction}

The aim of this article is to propose a new analytical framework for comparing and explaining the emergence and diffusion of European regional mountain initiatives (ERMIs), envisaged as 'functional regulatory spaces' (FRS) that emphasize intersectoral coordination, transterritorial cooperation, and multilevel governance. Regional mountain initiatives lend themselves to an assessment from the perspective of functional regulatory spaces. The adoption of the mountain chapter of Agenda 21 in 1992 and the subsequent consolidation of a global mountain agenda have signaled commitments vis-à-vis each of the three FRS axes. Coordination between

\footnotetext{
* Corresponding author at: Department of Geography and Environment, University of Geneva, Uni Mail, 40 Boulevard du Pont-d'Arve, 1211 Geneva, Switzerland. Tel.: +41 223979453.

E-mail address: joerg.balsiger@unige.ch (J. Balsiger).

http://dx.doi.org/10.1016/j.envsci.2015.01.004

1462-9011/(C) 2015 Elsevier Ltd. All rights reserved.
} 
sectors such as agriculture, transport, and nature conservation is generally recognized as a necessary element of modern policy making, not just in mountain regions. The importance of transterritorial coordination is implied by the cross-border reach of most mountain ranges. Vertical coordination as well as possible competence shifts across levels of government is increasingly called for in the name of multilevel governance.

The article examines three exploratory hypotheses. The first hypothesis considers that ERMIs can be compared, distinguished, and classified using the FRS approach (Varone et al., 2013). The analysis of ERMIs in seven mountain regions (Alps, Pyrenees, Jura, Carpathians, Balkan Mountains, Dinaric Arc, Caucasus; see Annex A for a list of the initiatives and countries involved) using the criteria of the FRS concept (transterritoriality, intersectorality, multilevel governance) allows us to compare, classify and propose a typology. In particular, it helps us to identify the main similarities and differences between the empirical cases and assess to what extent they converge with, or diverge from an ideal-type FRS. ${ }^{1}$

The second hypothesis addresses the relationship between the degree to which the different ERMIs correspond to an ideal-type FRS and their respective role and position in processes of policy diffusion. We hypothesize that the more an ERMI corresponds to the ideal-type FRS, the more important its role in diffusion processes. The reason for this is that the features associated with an ideal-type FRS intersectorality, transterritoriality, and multilevel governance - have become international policy norms linked to problemsolving capacity. In order to discuss this hypothesis, first we relate the typology of ERMIs as FRS to the temporal context of their emergence. This allows us to see if there is a relationship between the type of ERMI and the historical dynamic of its emergence and development. Second, we trace and categorize patterns of policy diffusion between the seven ERMIs (learning, adaptation, direct and indirect cooperation). Finally, we compare the FSR and policy diffusion typologies to identify the degree of collinearity.

The third hypothesis concerns the relationship between the degree of formalization and institutionalization of ERMIs and their role in policy diffusion processes. We hypothesize that the more and the earlier an ERMI is 'formalized' and 'institutionalized' in a clear and robust way as a 'mature' FRS, the more important its role, and the more central its position, in diffusion processes.

In its investigation of ERMI diffusion processes, this article focuses exclusively on the FRS features of transterritoriality, intersectorality, and multilevel governance. It does not consider other aspects of policy diffusion processes such as scientific cooperation (Debarbieux et al., 2014) or protected

\footnotetext{
${ }^{1}$ According to Max Weber, "an ideal-type is formed by the onesided accentuation of one or more points of view and by the synthesis of a great many diffuse, discrete, more or less present and occasionally absent concrete individual phenomena, which are arranged according to those one-sidedly emphasized viewpoints into a unified analytical construct ('Gedankenbild'). In its conceptual purity, this mental construct cannot be found empirically anywhere in reality. It is a utopia. Historical research faces the task of determining, in each individual case, the extent to which this ideal-construct approximates to or diverges from reality" (Weber, 1997 [1903-1917], p. 90).
}

areas networking. Moreover the scope of the article is limited to an analysis of the diffusion of policy designs and models. It does not take into account their implementation and impacts in the different mountain regions, although we flag this as important issue for future in-depth studies.

Overall, we emphasize that this article is a very first attempt to link FRS and policy diffusion approaches. As such it seeks to assess the link's feasibility and relevance, rather than a definitive empirical (in)validation of the three hypotheses. In particular, while our findings point to the existence of collinearity between an ERMI's convergence with an idealtype FRS and its position and role in policy diffusion, more detailed analysis will be required. We are nevertheless convinced that the preliminary insights we present in this article highlight an intriguing and previously unstudied phenomenon.

Our argument proceeds as follows. In Section 2, we provide brief theoretical synopses of functional regulatory spaces and policy diffusion as well as an outline of the exploratory hypotheses we investigate in the rest of the article. In Section 3 we present our empirical analysis of the seven ERMIs from the perspective of intersectorality, transterritoriality, multilevel governance, degree of formalization/institutionalization, and patterns of diffusion. In Section 4, we discuss the three hypotheses. Section 5 summarizes the argument and offers a number of recommendations for future research.

\section{Theory}

\subsection{The concept of functional regulatory space (FRS)}

Mountain ranges (or massifs) are frequently characterized by various sets of (more or less common) complex public problems such as economic and tourism development, environmental and landscape degradation, impacts of climate change, transit, poverty and depopulation, and collapse of agricultural systems. Some of these problems can be considered 'wicked problems': high-intensity public problems that result from multiple sets of complex interdependent causes, negatively affect large portions of a population, and to which high political priority should be accorded (Levin et al., 2012). Wicked problems characteristically transcend individual policy subsystems, institutional territories, and levels of government. Varone et al. (2013) developed the concept of 'functional regulatory space' (FRS) to assess how well state action is suited to address wicked problems. Thus, one of the objectives of this article consists in evaluating the relevance of considering ERMIs as FRS.

We define a FRS following Varone et al. (2013, p. 320):

“(. . .) a regulatory space, which politically emerges in order to tackle, support or solve problems concerning several policy sectors in different institutional territories and at different levels of government. (...) Thus, an FRS is a 'sociopolitical field' within the boundaries of which the (super) wicked problem is politically recognized by public and private stakeholders, who agree on the necessity of specific State intervention in order to solve it. In essence, an FRS is defined as a new regulatory space considered 
functionally appropriate - that is, geographically and socially relevant and politically legitimate - for the arbitration of rivalries and conflicts between the different groups of actors concerned.

FRSs are functional in the sense that they redefine the social and geographical spaces that are considered politically relevant for managing such problems. This redefinition process follows ad hoc criteria referring both to the physical area concerned in the problem and to the web of relationships linking stakeholders, rather than the existing boundaries of policy sectors, institutional territories or levels of government. In other words, FRSs are alternative regulatory spaces within which it becomes possible to tackle new types of problems that cut across various socioeconomic sectors as well as institutional territories and government levels.

The FRS concept enables the characterization and analysis of new forms of state action that cross policy subsystems, institutional territories, and levels of government and thereby helps describe and evaluate the scope and importance of the 'political rescaling process' (e.g. Brenner, 2004; Jouve, 2007) resulting from the emergence of FRS.

The concept further allows us to evaluate the extent to which a specific regulatory arrangement (for example the Alpine Convention or the Carpathian Convention) corresponds to the ideal type FRS. Thus, using the threedimensional analytical cube of a functional regulatory space (Fig. 1), we analyze five aspects of the seven ERMIs:

(1) Are wicked problems put on the political agenda within the perimeter of the ERMI?

(2) Does the ERMI define new hierarchies between policy sectors?

(3) Does the ERMI define new geographical boundaries beyond institutional territories?

(4) Does the ERMI define new divisions of competencies between levels of government?

(5) What is the degree of formalization and institutionalization of the ERMI?

We argue that the more an ERMI responds to wicked problems on the political agenda, consolidates policy integration across sectors, defines new geographical boundaries beyond institutional territories, redefines competences between levels of government, and is based on formal rules which are (on the way to be) institutionalized, the closer it is to the ideal type FRS.

Moreover, the comparison and identification of convergence or divergence between the empirical reality and the conceptual construct should stimulate the formulation of explanatory hypotheses concerning specific causal relationships between variables (Bourdieu et al., 1991). By doing so, it should help deepen and strengthen the comprehension of the specificities and similarities of the various empirical phenomena under observation (i.e., the emergence of FRS and political rescaling processes in our case). In this article, we will use the FRS ideal type, firstly, for comparing the various empirical

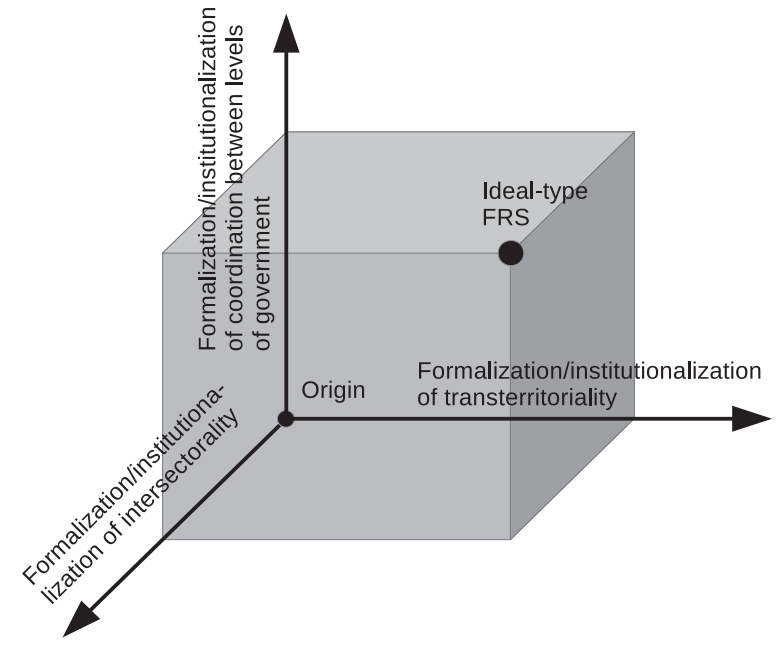

Fig. 1 - Four-dimensional analytical cube of a functional regulatory space. ${ }^{3}$

ERMIs and develop a typology (Hypothesis 1), and, secondly, for testing the hypothesis of a relationship between a specific type of ERMI and the role it plays within diffusion processes (Hypotheses 2 and 3).

\subsection{Policy diffusion processes}

Scholars from various social science disciplines have long sought to understand how ideas and practices spread through populations of individual and collective actors and what factors shape diffusion processes. Four different theoretical positions have been advanced to explain diffusion dynamics (Dobbin et al., 2007). Constructivists emphasize the role of policy norms and point to the importance of change agents such as epistemic communities and international organizations centrally involved in promulgating such norms and often coordinating their application. A related group of scholars suggests that countries learn from their own experiences or from those of others. A third type of explanations focuses on competition, for example between innovating firms or between countries wishing to attract investment by creating business-friendly environments. Finally, diffusion may manifest via coercion, where powerful nation states or international financial institutions devise carrots and sticks to enforce the implementation of certain practices.

Many policy diffusion studies have found that complete convergence is neither a necessary nor a likely outcome of diffusion and that norms, ideas and practices change as they diffuse (e.g. Börzel and Risse, 2012; Radaelli, 2005). According to Busch et al. (2005), while international promotion facilitates diffusion, its extent and speed is determined by the

\footnotetext{
${ }^{3}$ We consider the fourth dimension - degree of formalization/ institutionalization - as a cross-cutting dimension, hence its analysis and evaluation is directly integrated into the three axes of the cube.
} 
characteristics of what is diffused. Moreover, concerns of legitimacy and pressure to conform with international norms are often as much of a motivating force as the presumed rational drive of policy makers to improve effectiveness.

A recent synthesis of empirical work points to four factors that help explain why norms, ideas, and practices change as they move from source to adopter: the nature of the underlying diffusion model, the specificity of the item that is diffused, the type of diffusion mechanism in operation, and the institutional context at the point of adoption (KlinglerVidra and Schleifer, 2014). More convergence is to be expected when the diffusion process has a single, central source, whereas less convergence results in the presence of chain diffusion and multiple-source diffusion (Klingler-Vidra and Schleifer, 2014, p. 269). Similarly, research has found that multiple-source diffusion models enable hybridization, where elements from more than one source are combined (Falkner and Gupta, 2009).

In our analysis, we differentiate between two main types of diffusion, each with two subtypes. Following Elkins and Simmons (2005), we distinguish between diffusion and coordination but unlike them we consider coordination to be part of the overall class of diffusion mechanisms. Elkins and Simmons subdivide diffusion into learning and adaptation, and coordination into cooperation and coercion. We agree that coercion should be excluded but suggest that the difference between cooperation and learning is difficult to pin down in practice. According to Strang and Soule (1998), this stems from an ambiguity in diffusion studies concerning the contrast between observing practices and observing their outcomes. Since both of these can be at work in learning and cooperation, we consider the difference to be a matter of degree, not kind.

Within diffusion, we differentiate between learning and adaptation. Learning is linked to the premise that adoption depends more on external models of understanding the consequences of certain actions than on some internal repertoire of behavior (Bandura, 1977). Prominent learning mechanisms include information cascades (decisions of the first two or three actors determine the choices of an entire sequence of actors), availability (selection of immediately available or familiar models which may be linked to geographical proximity), and reference groups (preference for models used by similar actors) (Elkins and Simmons, 2005). Adaptation occurs when decisions by a source organization produce externalities for an adopter. Mechanisms that foster adaptation can include cultural norms that increase reputational benefits and support groups providing access to technical and financial sources (Elkins and Simmons, 2005). Within cooperation, we differentiate between direct and indirect cooperation. In direct cooperation, organizations that are part of the source are themselves involved in the diffusion, for instance when the Permanent Secretariat of the Alpine Convention organizes a conference for assessing opportunities to export its governance model to other mountain regions. Indirect cooperation involves third parties such as non-governmental organizations linked to, but not formally part of a source entity, such as the European Academy Bolzano or the Swiss Group for Mountain Regions. Because cooperation often occurs in the context of time-bound programs or projects, this type of mechanism, especially the direct variant, is likely to produce more rapid diffusion than learning and adaptation.

\subsection{Exploratory hypotheses}

We discuss three exploratory hypotheses. The first hypothesis simply states that since all ERMI designs incorporate some degree of intersectorality, transterritoriality, and multilevel governance, they can be characterized, analyzed, and compared using the FRS approach. Thus, an assessment of governance arrangements in the Alps, Pyrenees, Jura, Carpathians, Balkan Mountains, Dinaric Arc, and Caucasus should allow us to identify their main similarities and differences and to evaluate the extent to which they converge with, or diverge from the FRS ideal-type and hence to propose a typology of ERMIs (Section 3.1). In order to appraise the relevance of the FRS approach for typologizing the various ERMIs, we systematically compare their empirical features with the ideal typical definition of a FRS, using criteria related to the above mentioned analytical dimensions: sectoral scope and redefinition of hierarchies between policy sectors; designation of new institutional territories; and reordering of multilevel governance.

The second hypothesis focuses on the relationship between an ERMI's proximity to the FRS ideal-type and its role and position within policy diffusion processes. More precisely, we assume that the more an ERMI corresponds to the idealtype of a FRS, the more important its role, and the more central its position, in diffusion processes. We address two key dimensions of this hypothesis. First, we situate the typology of ERMIs in historical time in order to evaluate whether certain types emerge at certain times. Second, we analyze the historical patterns of ERMI emergence and development in relation to policy diffusion models (diffusion: learning or adaptation; coordination: direct or indirect cooperation) in order to identify common policy diffusion phenomena between the various ERMIs types. Finally, we compare the two typologies (ERMIs as FRS and policy diffusion between ERMIs) and verify the degree of collinearity.

The third hypothesis considers the relationship between an ERMI's degree of formalization and institutionalization and its role in policy diffusion processes. We expect that the earlier an ERMI is solidly formalized and institutionalized as a FRS, the more significant its role as a source of diffusion (rather than an adopter), and the more central its position in the diffusion process. To discuss this hypothesis, we compare the degree of formalization and institutionalization of each ERMI with its role and position in policy diffusion.

\section{Empirical results}

In this section we provide an overview of our empirical assessment of ERMIs as functional regulatory spaces and of patterns of diffusion. The objective is to set the stage for an analysis of the relationship between the two and hence answer our three hypotheses. The overview is presented in two subsections. In Section 3.1 we assess intersectorality, transterritoriality, multilevel governance, and degree of 
formalization/institutionalization for each of the seven ERMIs. Section 3.2 sheds light on the channels and modes of diffusion. Our analysis is based on findings from several research projects and related publications (Balsiger, 2009, 2012; Debarbieux and Rudaz, 2010; Debarbieux et al., 2013, 2014; Djordjevic, 2014; Djordjevic and Balsiger, 2012; Gaberell, 2013, 2014; Gaberell and Debarbieux, 2014), where empirical work was carried out by means of extensive individual and focus group interviews, participant observation, and text analysis of primary and secondary sources.

We note two caveats. First, the regional mountain initiatives analyzed here are at very different stages. At one end of the spectrum is the Alpine Convention, which was signed in 1991 and has been in force for almost 20 years. At the other end are initiatives that entail ministerial declarations or draft conventions, notably in the case of Southeast Europe and the Caucasus. We incorporate this variety into our analysis by means of the fourth FRS dimension of degree of formalization and institutionalization. Second, regional governance in mountain ranges often involves multiple policy instruments and programs. In the Alps, for example, the Alpine Convention is paralleled by the European Union Alpine Space Program, and subregional initiatives such as Espace Mont-Blanc. Where such initiatives reveal a declaratory link to mountain governance, we include them in our assessment unless otherwise noted. For example, whereas the Carpathians and the Alps are both home to EU transnational cooperation programmes that involve transterritorial cooperation between subnational entities, the Alpine Space Programme refers to a mountain range whereas the Danube Programme does not; hence we would conclude that transterritoriality and multilevel governance in the Alps is more pronounced than in the Carpathians.

\subsection{Typology of ERMIs}

The detailed operationalization of complex concepts such as transterritoriality and vertical coordination in regional governance systems is a challenging task that is beyond the scope of this article. Since our intent is to locate the seven ERMIs relative to each other (with respect to an ideal-type FRS), however, the absolute positioning on the FRS axes is not imperative and can be left to future in-depth case studies. Instead, we resort to pairwise comparison with the exception of intersectoral scope, illustrating our assessments with selected examples. At the same time, pairwise comparison allows us to consider certain qualitative aspects such as the intensity of coordination, rather than simply the presence or absence of, say, coordinating institutions. Pairwise comparison, a technique that emerged from the analytic hierarchy process (Saaty, 1980), is widely used in multicriteria decision making.

\subsubsection{Intersectorality}

Regional mountain initiatives have traditionally emphasized the importance of policy integration, or at least the consideration of cross-sectoral interdependence. Article 2 of the Carpathian Convention calls on Parties to promote "integrated planning and management of land and water resources" as well as ecosystem approaches (Carpathian Convention, 2003). Similarly, the signatories of the 2011 Resolution on the
Sustainable Development of the Dinaric Arc Region emphasize "the need for an integrated approach in achieving sustainable development in the region (Dinaric Arc Resolution, 2011).

Complex sectoral interdependence is also one of the main reasons why we consider that sustainable mountain development (SMD) as such is a wicked problem. In the original definition of wicked problems, Rittel and Webber (1973) further suggest that there is no definite formulation of a wicked problem, that solutions are not true-or-false but goodor-bad, that there is not even readily available list of potential solutions, and that every wicked problem is unique. This last feature is important because SMD evolves around a slightly different set of issues in each ERMI. While detailed comparison of the nature of these wicked problems is beyond the scope of this article, we note that SMD issues that appear in almost all ERMIs include environmental protection (especially air pollution and biodiversity conservation), transport, and socioeconomic development.

In order to assess the intersectoral scope of the seven ERMIs, we analyzed their foundational documents with a focus on the "peak" agreement (Table 1). This includes the convention and protocol texts as well as relevant declarations of the Alpine and Carpathian conventions, the charters of the Jura and Pyrenees Working Communities, and the ministerial declarations or draft conventions for the Dinaric Arc, Balkan Mountains and the Caucasus.

Table 1 shows the sectors mentioned explicitly in these documents. Clearly, not all sectors have the same weight; even the same sectors may vary in importance from one ERMI to another. Moreover, some of these sectors may overlap (e.g. climate and air pollution) and some ERMIs may treat multiple sectors under one heading (e.g. waste under urban development, or Research under Economy/Training). Nevertheless, the founding documents provide insights into how sectorally varied the respective promoters understood the respective mountain policy domain, and hence how extensive intersectoral cooperation was seen to be needed.

Table 1 reveals that the most sectors are mentioned for the Alps and Jura, followed by the Balkan Mountains and the Caucasus, the Carpathians and Dinaric Arc, and finally the Pyrenees. Of note is the fact that although the Alpine Convention is often characterized as an environmental treaty, its sectoral scope is wider than that of most other ERMIs.

A look at the sectoral scope identified in foundational documents does not tell us anything about whether the actual or planned establishment of an ERMI changes the sectoral pecking order. Prior research suggests that while environmental concerns generally moved up on policy agendas in the Carpathians, Southeast Europe, and the Caucasus, not least due to the instrumental role played by the United Nations Environment Programme (UNEP), socio-economic concerns were consolidated in Western Europe due to the close operational links between ERMIs with EU transnational programmes required to be oriented towards the European growth agenda (Balsiger, 2012; Debarbieux and Rudaz, 2010; Debarbieux et al., 2013; Djordjevic and Balsiger, 2012; Gaberell, 2014).

\subsubsection{Transterritoriality}

The second axis of our FRS cube refers to transterritoriality. We distinguish between three dimensions. The first 
Table 1 - Intersectorality.

\begin{tabular}{|c|c|c|c|c|c|c|c|}
\hline & Alps $^{a}$ & Pyrenees $^{b}$ & Jura $^{\mathrm{c}}$ & Carpathians $^{\mathrm{d}}$ & Balkan Mountains ${ }^{\mathrm{e}}$ & Dinaric Arc ${ }^{f}$ & Caucasus $^{g}$ \\
\hline Nature & $\mathrm{x}$ & $\mathrm{x}$ & $\mathrm{x}$ & $\mathrm{x}$ & $\mathrm{x}$ & $\mathrm{x}$ & $\mathrm{x}$ \\
\hline Agriculture & $\mathrm{x}$ & & $\mathrm{x}$ & $\mathrm{x}$ & $\mathrm{x}$ & $\mathrm{x}$ & $\mathrm{x}$ \\
\hline Forestry & $\mathrm{x}$ & & $\mathrm{x}$ & $\mathrm{x}$ & $\mathrm{x}$ & $\mathrm{x}$ & $\mathrm{x}$ \\
\hline Tourism & $\mathrm{x}$ & $\mathrm{x}$ & $\mathrm{x}$ & $\mathrm{x}$ & $\mathrm{x}$ & $\mathrm{x}$ & $\mathrm{x}$ \\
\hline Land use planning & $\mathrm{x}$ & $\mathrm{x}$ & & $\mathrm{x}$ & & $\mathrm{x}$ & $\mathrm{x}$ \\
\hline Urban development & & & $\mathrm{x}$ & & & & \\
\hline Energy & $\mathrm{x}$ & & $\mathrm{x}$ & $\mathrm{x}$ & $\mathrm{x}$ & $\mathrm{x}$ & $\mathrm{x}$ \\
\hline Soils & $\mathrm{x}$ & & & & & & $\mathrm{x}$ \\
\hline Transport & $\mathrm{x}$ & $\mathrm{x}$ & $\mathrm{x}$ & $\mathrm{x}$ & $\mathrm{x}$ & $\mathrm{x}$ & $\mathrm{x}$ \\
\hline Culture & $\mathrm{x}$ & $\mathrm{x}$ & $\mathrm{x}$ & $\mathrm{x}$ & $\mathrm{x}$ & $\mathrm{x}$ & $\mathrm{x}$ \\
\hline Health & & & $\mathrm{x}$ & & & & \\
\hline Social policy & & & $\mathrm{x}$ & & & & \\
\hline Air pollution & $\mathrm{x}$ & & & & $\mathrm{x}$ & & $\mathrm{x}$ \\
\hline Water & $\mathrm{x}$ & & & $\mathrm{x}$ & $\mathrm{x}$ & $\mathrm{x}$ & $\mathrm{x}$ \\
\hline Waste & $\mathrm{x}$ & & & & $\mathrm{x}$ & & $\mathrm{x}$ \\
\hline Climate & $\mathrm{x}$ & & & $\mathrm{x}$ & & & \\
\hline Economy/Training & & $\mathrm{x}$ & $\mathrm{x}$ & & & & \\
\hline Communication/ICT & & & $\mathrm{x}$ & & & & \\
\hline Research & & $\mathrm{x}$ & $\mathrm{x}$ & & $\mathrm{x}$ & & \\
\hline Sports & & $\mathrm{x}$ & & & & $\mathrm{x}$ & \\
\hline Mining & & & & & $\mathrm{x}$ & & \\
\hline Total & 13 & 8 & 13 & 10 & 12 & 10 & 12 \\
\hline Rank & 1 & 4 & 1 & 3 & 2 & 3 & 2 \\
\hline $\begin{array}{l}\text { a Alpine Convention, } \\
\text { b Objectives of the C } \\
\text { c Convention Comm } \\
\text { d Carpathian Conven } \\
\text { e Draft Framework C } \\
\text { f Ministerial Resoluti } \\
\text { g Draft Convention fo }\end{array}$ & $\begin{array}{l}\text { munals, } \\
\text { uté de T } \\
\text { and } \mathrm{Pr} \\
\text { ention } \mathrm{f} \\
\text { concerni } \\
\text { he Prote }\end{array}$ & $\begin{array}{l}\text { Declarations } \\
\text { Travail des } \\
\text { ail du Jura. } \\
\text { cols. } \\
\text { the Protectior } \\
\text { the Sustaina } \\
\text { n of the Cau }\end{array}$ & $\begin{array}{l}\text { Susta } \\
\text { Sevelor } \\
\text { s Mour }\end{array}$ & $\begin{array}{l}\text { ble Developmen } \\
\text { nt of the Dinaric } \\
\text { n Ecosystem. }\end{array}$ & $\begin{array}{l}\text { me priorities. } \\
\text { Mountain Regions of } \\
\text { c Region. }\end{array}$ & heast Europe. & \\
\hline
\end{tabular}

dimension relates to the degree to which a given mountain governance arrangement includes provisions for the creation of new, clearly defined regulatory spaces whose logic of action transcends existing institutional territories. The second concerns the willingness of participating parties to cede some degree of sovereignty in the interest of solving common problems (e.g. the provision of public goods). The third gives an indication of the degree of autonomy granted to subnational authorities for negotiating transterritorial (domestic or international) agreements.

Table 2 summarizes horizontal coordination between institutional territories at the interstate, crossborder, and intermunicipal level. Here, we use pairwise comparison to develop a ranking of the extent of cooperation in the seven ERMIs; analyzing in detail the quality of transterritorial cooperation would be beyond the scope of this paper. The number triples in cells refer to interstate, interregional/crossborder, and inter-municipal cooperation, respectively. With the direction of comparisons proceeding from column entries to row entries, -1 means the column ERMI ranks less favorable than the row ERMI, 0 means they are similar, and 1 means the column ERMI ranks more favorable than the row ERMI. The last two columns show the sum of pairwise comparisons for a given ERMI as well as the ranking.

Our assessment shows that relatively speaking, the governance system in the Alps is closest to an ideal-type FRS. This can be explained on the basis of an intergovernmental treaty that has existed for more than two decades; extensive cross-border cooperation, both in the context of the
Alpine Space Programme and in subregional arrangements; and by well-developed inter-municipal institutions, including those mandated by established mountain laws in Switzerland and France.

The Alps are followed by the Pyrenees and the Jura, where intergovernmental instruments exist, but do not have the same status as the Alpine Convention. The Pyrenees ERMI is ahead of its counterpart in the Jura because while the Working Community for the Pyrenees has managed to obtain legal personality (through the creation of a "Consorcio" under Spanish law) and assume official ownership of the Operational Programme for Transboundary Cooperation between Spain, France, and Andorra (Poctefa), the Conférence TransJurassienne has managed no equivalent feat. The Balkan Mountains, Dinaric Arc, and Caucasus ERMIs rank last on an equal footing because relatively little interstate, cross-border, and intermunicipal coordination can be observed. While it is true that there are cross-border initiatives in the Balkan Mountains and the Dinaric Arc areas, primarily through EU programs, these rarely make reference to the mountain agenda.

\subsubsection{Multilevel governance}

The third axis of the FRS cube captures the extent and reorganization of vertical cooperation between different levels of government that is introduced with the (actual or proposed) establishment of an ERMI. Two different dimensions are included in this assessment. The first relates to the number of governance levels that constitute an ERMI's vertical cooperation system (analyzing in depth the quality of cooperation is 
Table 2 - Pairwise comparison: transterritoriality.

\begin{tabular}{llllcccccc} 
& Alps & Pyrenees & Jura & Carpathians & Balkans & Dinaric Arc & Caucasus & Total & Position \\
\hline Alps & $\|$ & $1 / 1 / 0$ & $1 / 1 / 1$ & $1 / 1 / 1$ & $1 / 1 / 1$ & $1 / 1 / 1$ & $1 / 1 / 1$ & 17 & 1 \\
Pyrenees & $-1 /-1 / 0$ & $\mathbb{}$ & $0 / 0 / 1$ & $0 / 1 / 1$ & $1 / 1 / 1$ & $1 / 1 / 1$ & $1 / 1 / 1$ & 10 & 2 \\
Jura & $-1 /-1 /-1$ & $0 / 0 /-1$ & $\mathbb{}$ & $0 / 1 / 1$ & $1 / 1 / 1$ & $1 / 1 / 1$ & $1 / 1 / 1$ & 7 & 3 \\
Carpathians & $-1 /-1 /-1$ & $1 /-1 /-1$ & $1 /-1 /-1$ & $\|$ & $1 / 1 / 1$ & $1 / 1 / 1$ & $1 / 1 / 1$ & 4 \\
Balkans & $-1 /-1 /-1$ & $-1 /-1 /-1$ & $-1 /-1 /-1$ & $-1 /-1 /-1$ & $1 /$ & $0 / 0 / 0$ & $0 / 0 / 0$ & -12 & 5 \\
Dinaric Arc & $-1 /-1 /-1$ & $-1 /-1 /-1$ & $-1 /-1 /-1$ & $-1 /-1 /-1$ & $0 / 0 / 0$ & 11 & $0 / 0 / 0$ & -12 & 5 \\
Caucasus & $-1 /-1 /-1$ & $-1 /-1 /-1$ & $-1 /-1 /-1$ & $-1 /-1 /-1$ & $0 / 0 / 0$ & $0 / 0 / 0$ & $\|$ & -12 & 5 \\
\hline
\end{tabular}

Table 3 - Pairwise comparison: multilevel governance.

\begin{tabular}{llllcccccc} 
& Alps & Pyrenees & Jura & Carpathians & Balkans & Dinaric Arc & Caucasus & Total & Position \\
\hline Alps & $\|$ & $-1 /-1$ & $-1 / 0$ & $1 / 1$ & $1 / 1$ & $1 / 1$ & $1 / 1$ & 5 & 3 \\
Pyrenees & $1 / 1$ & $\|$ & $0 / 1$ & $1 / 1$ & $1 / 1$ & $1 / 1$ & $1 / 1$ & 11 & 1 \\
Jura & $1 / 0$ & $0 /-1$ & $\|$ & $1 / 1$ & $1 / 1$ & $1 / 1$ & $1 / 1$ & 8 \\
Carpathians & $-1 /-1$ & $-1 /-1$ & $-1 /-1$ & $\|$ & $0 / 1$ & $0 / 1$ & $0 / 1$ & -3 & 2 \\
Balkans & $-1 /-1$ & $-1 /-1$ & $-1 /-1$ & $0 / 0$ & $\|$ & $0 / 0$ & $0 / 0$ & -6 & 5 \\
Dinaric Arc & $-1 /-1$ & $-1 /-1$ & $-1 /-1$ & $0 / 0$ & $0 / 0$ & 11 & $0 / 0$ & -6 & 5 \\
Caucasus & $-1 /-1$ & $-1 /-1$ & $-1 /-1$ & $0 / 0$ & $0 / 0$ & $0 / 0$ & 11 & -6 \\
\hline
\end{tabular}

beyond the scope of this article). The second dimension refers to the degree to which competences are redistributed between levels of government. For our assessment in Table 3 we use pairwise comparison in the same way as in the preceding section, but the number pairs in cells now refer to extent and redistributive impact of vertical cooperation, respectively.

Table 3 reveals both similarities and differences to the comparison of ERMI transterritoriality. Most prominently, the order of the first three positions is reversed. Our assessment places the Pyrenees first, the Jura second, and the Alps third. As concerns the scope and intensity of vertical cooperation, the Jura and Pyrenees ERMIs are fairly similar. Both have regional working communities established through interstate and inter-regional agreements, where municipalities play a similar advisory role. However, we rank the Pyrenees somewhat higher because of the stronger role in operational matters of the regional level (through the Consorcio). Although there are also working communities in the Alps, they are subregionally fragmented and their establishment did not involve the state level. On the other hand, the Alpine Convention is almost purely intergovernmental affair, which has negatively affected the quality of vertical cooperation.

As in the case of transterritoriality, the Carpathians hold an intermediary position between the three ERMIs of Western Europe and the three ERMIs of Central and Southeast Europe and the Caucasus. The Carpathian Convention, similar to its Alpine counterpart, is heavily oriented towards interstate cooperation. Moreover, subnational governance levels are not nearly as strongly developed as in the Alps, Pyrenees, Jura, or have even experienced setbacks as in the recent history of Hungary (Lewis and Benson, 2014).

\subsubsection{Degree of formalization and institutionalization}

This fourth pairwise comparison differentiates the seven ERMIs from the perspective of degree of formalization and institutionalization. To this end we carried out a qualitative assessment of the ERMIs under the following three criteria: (1) legal status of the founding document; (2) number, scope, density, clarity, and robustness of ERMI rules; and (3) state of implementation and translation of ERMI rules into national law. The assessment is based on the most formal and institutionalized instrument specific to each ERMI.

Table 4 shows the pairwise comparison of degree of formalization and institutionalization. The two most formalized and institutionalized ERMIs are in the Alps and the Carpathians, where intergovernmental treaties with a framework convention and several protocols have been signed and ratified by most parties. The two conventions are followed by the Pyrenees and the Jura, where Working Communities were formally established. We rank the Pyrenees higher because since 2005, the CTP's status as a Consorcio under Spanish law has provided it with a level of legal rights the CTJ does not have. Among the remaining three ERMIs, we rank the Caucasus and Dinaric Arc higher because cooperation in these mountain regions was formalized in a ministerial declaration, while no similar instrument was ever elaborated in the Balkan Mountains.

\subsubsection{ERMI typology}

Our evaluation of the seven ERMIs on the basis of the three FRS axes and the degree of formalization and institutionalization can now be brought together. Table 5 illustrates the respective ranks. Note that first place does not mean that the given ERMI is on par with an ideal-type FRS with respect to the given axis, but that it comes closest relative to the other ERMIs.

A number of characteristics illustrated in Table 5 and Fig. 2 are worth highlighting; more detailed discussion will follow in Section 4. First, none of the ERMIs rank the same way on all four axes, although the Southeast European and Caucasus ERMIs have the same rank for transterritoriality and multilevel governance. As we will show in the next section, this absence of collinearity allows us to assess differentiated relationships between FRS axes and patterns of policy diffusion. 
Table 4 - Pairwise comparison: degree of formalization and institutionalization.

\begin{tabular}{|c|c|c|c|c|c|c|c|c|c|}
\hline & Alps & Pyrenees & Jura & Carpathians & Balkans & Dinaric Arc & Caucasus & Total & Rank \\
\hline Alps & 11 & 1 & 1 & 0 & 1 & 1 & 1 & 5 & 1 \\
\hline Pyrenees & -1 & 11 & 1 & -1 & 1 & 1 & 1 & 2 & 2 \\
\hline Jura & -1 & -1 & 11 & -1 & 1 & 1 & 1 & 0 & 3 \\
\hline Carpathians & 0 & 1 & 1 & 11 & 1 & 1 & 1 & 5 & 1 \\
\hline Balkans & -1 & -1 & -1 & -1 & 11 & -1 & -1 & -6 & 5 \\
\hline Dinaric Arc & -1 & -1 & -1 & -1 & 1 & 11 & 0 & -3 & 4 \\
\hline Caucasus & -1 & -1 & -1 & -1 & 1 & 0 & 11 & -3 & 4 \\
\hline
\end{tabular}

\section{Table 5 - Summary overview of ERMI ranks on FRS axes.}

\begin{tabular}{|c|c|c|c|c|c|c|}
\hline & Intersectorality & Transterritoriality & $\begin{array}{c}\text { Multilevel } \\
\text { Governance }\end{array}$ & $\begin{array}{c}\text { Degree of } \\
\text { institutionalization }\end{array}$ & Total & $\begin{array}{l}\text { Cumulative } \\
\text { rank }\end{array}$ \\
\hline Alps & 1 & 1 & 3 & 1 & 6 & 1 \\
\hline Pyrenees & 4 & 2 & 1 & 2 & 9 & 2 \\
\hline Jura & 1 & 3 & 2 & 3 & 9 & 2 \\
\hline Carpathians & 3 & 4 & 4 & 1 & 12 & 3 \\
\hline Balkan Mountains & 2 & 5 & 5 & 5 & 17 & 5 \\
\hline Dinaric Arc & 3 & 5 & 5 & 4 & 17 & 5 \\
\hline Caucasus & 2 & 5 & 5 & 4 & 16 & 4 \\
\hline
\end{tabular}

Second, while the ranks can be summed up, as we do in the last column of Table 5, this would assume that the three axes are weighted equally. Moreover, it would assume that the respective axes are interval scales. In reality, our approach using pairwise comparison results in an ordinal scale, where the difference between first and second does not need to be the same as between second and third, third and fourth, and so on. For the same reason, ranking first on any axis does not say anything about the absolute proximity to the ideal-type FRS. This is an issue we will return to in the conclusion.

Third, although the Alps are often considered a model of mountain governance, our assessment shows that this is not so on all accounts. Finally, one cannot help noticing that there is an East-West gradient, where the Carpathians take up a middle position between the Alpine, Jura, and Pyrenees ERMIs and the Southeast European and Caucasus ERMIs.

\subsection{Patterns of policy diffusion}

With the emergence of a global mountain agenda in the early 1990s and the visible involvement of international actors in its promotion, it should not come as a surprise that regional mountain initiatives have spread to many parts of the world. Even before the adoption of the mountain chapter in Agenda 21, however, regional cooperation in mountain areas became prominent in Western Europe through working communities in the Alps, Pyrenees and the Jura between the early 1970s and mid-1980s. As a result, the nature and directions of policy diffusion show considerable diversity in time and space.
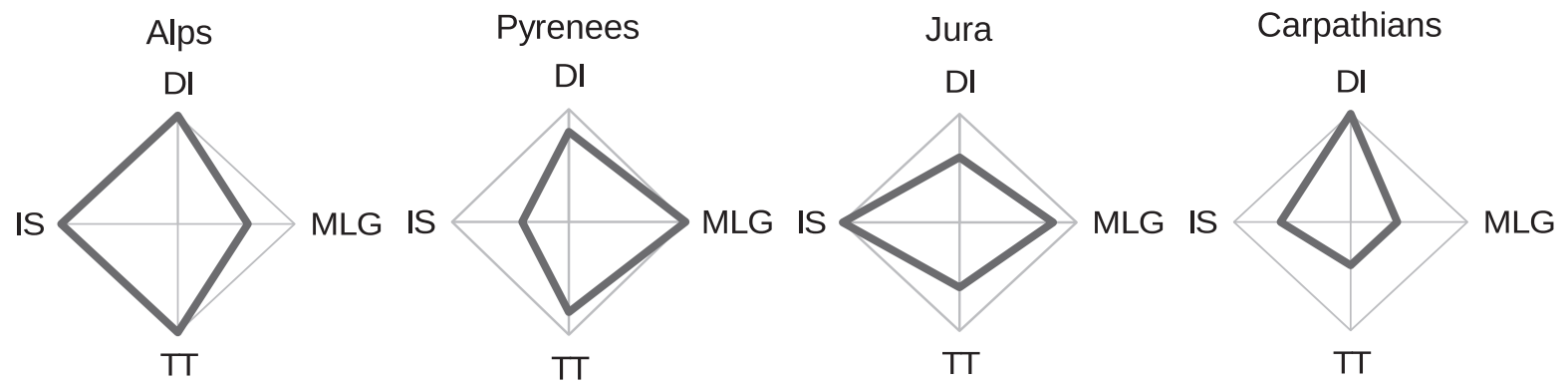

Balkan Mountains

Dinaric Arc

\section{Caucasus}
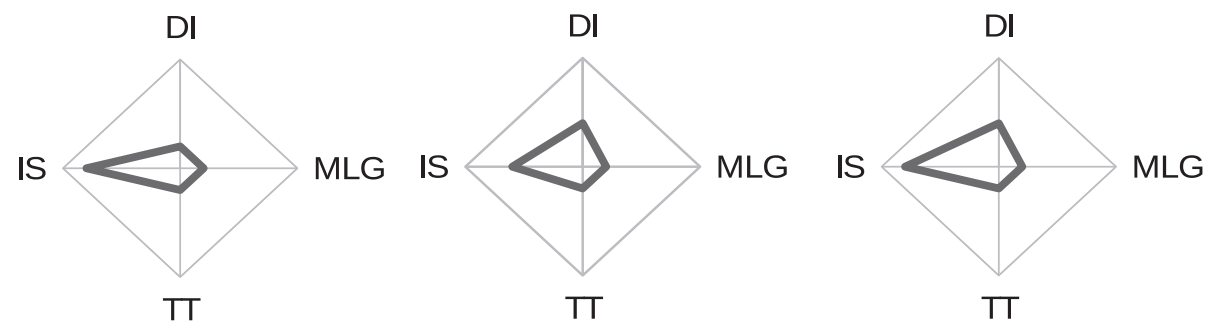

Fig. 2 - ERMI FRS in four-dimensional space. 


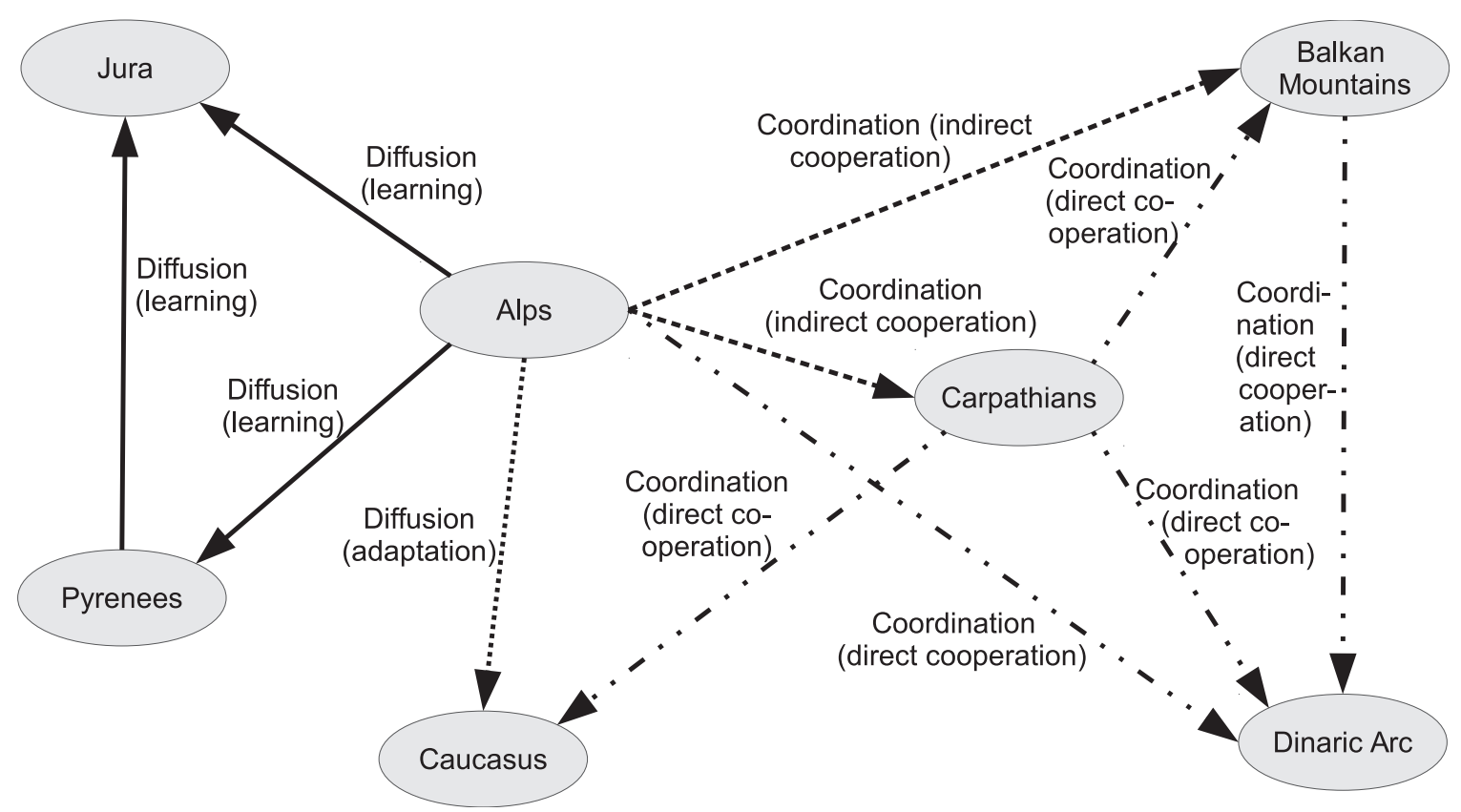

Fig. 3 - Diffusion patterns between European regional mountain initiatives.

Fig. 3 provides an overview of the spread of ERMIs since the early 1970s. ${ }^{2}$ Three important dimensions can be characterized in the figure: direction, type, and centrality. The direction of diffusion simply distinguishes between a source and an adopter. In terms of the overall definition of policy diffusion, it means that a choice made by the decision-makers in the source influences the choice(s) made by decision-makers of the adopter. For instance, the establishment of a working community among subnational governments in the Western Alps in 1972 influenced the subsequent creation of working communities in the southeastern and southwestern Alps. In accordance with the theoretical discussion of policy diffusion in Section 2.2, types of diffusion refer to the core mechanisms: diffusion (learning or adaptation) and coordination (direct or indirect cooperation). Centrality refers to the number of incoming and outgoing links of a given ERMI. Since we are primarily interested in directional links from source to adopter, we focus on out-degree centrality (Busch et al., 2005; Wasserman and Faust, 1994). The greater the number of outgoing links (as a ratio of the total number of possible links in the network), the greater an ERMI's centrality and hence the more important its overall role in the spread of a policy.

In view of the large number of state actors, and international governmental and non-governmental actors involved in the development and implementation of a regional mountain initiative, tracing all links between the seven ERMIs would be an enormous task. Indeed, any given link is but a general tendency among multiple types and directionalities, not least because the same individuals are often involved in more than one initiative, thereby constituting a diffusion channel that

\footnotetext{
2 The empirical evidence for this synthesis of diffusion patterns originates from a series of research projects (see Acknowledgments).
}

may involve extensive back-and-forth exchange of views and experiences. For these reasons, Fig. 3 focuses only on the dominant patterns.

Four different patterns of diffusion can be identified:

Diffusion (learning): Alps $\rightarrow$ Pyrenees, Alps $\rightarrow$ Jura, and Pyrenees $\rightarrow$ Jura (1970s-1980s). This type of diffusion finds its origins in the efforts by the Council of Europe to promote cross-border cooperation between subnational regions, which started in the 1960s and led to the 1980 Madrid Convention on Cross-border Cooperation between territorial entities (the Madrid Convention) (De Sousa, 2013). Working Communities were established in the eastern Alps (Arge Alp, 1972), the Adriatic Alps (Alpe-Adria, 1978), the western Alps (Cotrao, 1982), the Pyrenees (CTP, 1983), and the Jura (CTJ, 1985). The content of diffusion was both substantive (a regional and intersectoral focus on mountain areas) and procedural (an institutional model for cross-border cooperation).

Diffusion (adaptation): Alps $\rightarrow$ Caucasus (since late 1990s). Although the adaptation variant of diffusion, which designates situations in which policy decisions of one set of actors change the conditions under which other actors reach their decisions, is present in most cases of diffusion, it is rarely the dominant mechanism. We consider the link between the Alps and the Caucasus to be of this type because of the role of cultural norms and support groups (Elkins and Simmons, 2005, pp. 39-41).

Coordination (direct cooperation): Carpathians $\rightarrow$ Balkan Mountains, Carpathians $\rightarrow$ Dinaric Arc, Carpathians $\rightarrow$ Caucasus, Balkan Mountains $\rightarrow$ Dinaric Arc, Alps $\rightarrow$ Dinaric Arc (all since 2000s). This set of links shares the important feature of being driven by the same international actor (except in the case of Alps $\rightarrow$ Dinaric Arc, where direct cooperation results from the fact that Slovenia is both a party to the Alpine Convention and the driving force behind the Dinaric Arc Resolution). The UNEP 
Table 6 - Core dimensions of diffusion patterns.

\begin{tabular}{|c|c|c|c|c|}
\hline & Dominant directionality & Out-degree centrality & In-degree centrality & FRS diffusion potential \\
\hline Alps & Outgoing & $6 / 6$ & $0 / 6$ & High \\
\hline Pyrenees & Balanced & $1 / 6$ & $1 / 6$ & Low \\
\hline Jura & Incoming & $0 / 6$ & $2 / 6$ & Low \\
\hline Carpathians & Outgoing & $3 / 6$ & $1 / 6$ & Medium \\
\hline Balkan Mountains & Incoming & $1 / 6$ & $2 / 6$ & Low \\
\hline Dinaric Arc & Incoming & $0 / 6$ & $3 / 6$ & Low \\
\hline Caucasus & Incoming & $0 / 6$ & $2 / 6$ & Low \\
\hline
\end{tabular}

Regional Office for Europe in Vienna, which has been instrumentally involved in the development of the Carpathian Convention and which administers the Convention's Interim Secretariat, has been actively involved in Southeast Europe and the Caucasus. This involvement has entailed both political efforts surrounding the elaboration of draft conventions for the Balkan Mountains and the Caucasus and the Ministerial Declaration for the Dinaric Arc, and the promotion of scientific cooperation in these regions.

Coordination (indirect cooperation): Alps $\rightarrow$ Carpathians (since 1990s) and Alps $\rightarrow$ Balkan Mountains (2000s). The dominant type of link here is indirect cooperation via third party organizations. In the first case, the link between the Alps and the Carpathians was via organizations such as the European Academy of Bolzano, which engages in applied research but also has a mandate from the Italian Ministry of Foreign Affairs to provide policy advice in the domain of regional mountain cooperation. In the second case, the mechanism involved the support of the Swiss Agency for Development and Cooperation, the Swiss Group for Mountain Regions (SAB) and Euromontana to the establishment of national mountain organizations in seven Balkan countries (later consolidated into Romontana, Makmontana and Bulmontana) (Euromontana, 2014).

Table 6 summarizes the diffusion profiles of the seven ERMIs. In terms of the dominant directionality, it stands out that only the Alps and the Carpathians have predominantly outgoing links. However, whereas all outgoing links from the Carpathians involve direct cooperation (through UNEP), four different types of diffusion mechanisms are present for the Alps; outgoing diffusion from the Alps has also occurred over a much longer period of time, and through more diverse channels, than from the Carpathians. Among the ERMIs predominantly having incoming links, the Jura stands alongside Southeast Europe and the Caucasus. The two ERMIs with predominantly outgoing links also have the highest outdegree centrality, while most other ERMIs score rather low. The third column provides a combined assessment of an ERMI's diffusion potential, which we will analyze in the context of functional regulatory spaces in the next section. The Alps and the Carpathians have the highest diffusion potential.

\section{Discussion}

In this section, we discuss the three exploratory hypotheses presented in Section 2.3.

\subsection{Hypothesis 1}

We find that the FRS approach lends itself well for analyzing and comparing regional mountain initiatives in Europe.

Firstly, the comparison of the seven empirical ERMIs with the FRS ideal type shows that none of them meets all the criteria of an 'accomplished' FRS. Even the Alpine Convention, which comes closest to the ideal type on the axis of intersectorality and transterritoriality, diverges from the ideal type by its lower extent and weaker reorganization of vertical cooperation between different levels of government, as well as by the lower degree to which competences are redistributed between levels of government.

Secondly, the FRS approach allows us to characterize and compare ERMIs according to their respective proximity (or distance) to the FRS ideal type. As a result we can identify three different clusters of ERMIs. A first cluster consists of the 'old' Western European ERMIs (Alps, Jura, Pyrenees), which are the closest to the ideal type. A second cluster includes the first Eastern European ERMI (Carpathians). This ERMI has developed FRS features on the three axis simultaneously, but at a lower level than the Western European ERMIs. Finally a third cluster composed of the emerging Southeastern European (Balkan Mountains, Dinaric Arc) and Caucasus ERMIs, which are still quite distant from the FRS ideal type on all three axes.

Thirdly, in the case of Western European ERMIs, progress in transterritoriality and multilevel governance seems to have taken precedence over the search for intersectoral solutions to wicked problems. We refer to this as an 'institution building oriented trajectory'. By contrast, in the case of the Southeastern European and Caucasus ERMIs, the search for coordinated intersectoral solutions appears to trump the formalization and institutionalization of transterritorial and multilevel governance arrangements. We refer to this as a 'problem oriented trajectory' (see Fig. 2). These contrasting trajectories could be explained by the fact that in the case of Western European ERMIs, implementation has drawn almost exclusively on funding from EU cohesion policy, which emphasizes transterrritoriality and multilevel governance much more than intersectorality.

\subsection{Hypothesis 2}

Our second hypothesis suggests that there is positive correlation between an ERMI's proximity to the FRS ideal type and its role and position within policy diffusion processes. First, this hypothesis is largely confirmed if we consider the cumulative ranks on all four FRS dimensions. At one end of the spectrum, the Alpine ERMI is simultaneously the closest to an 
ideal type FRS and the most central ERMI in the overall diffusion landscape. At the other end of the spectrum are the Southeast European ERMIs, which are the most distant from an ideal-type FRS and play a small role in diffusion.

Second, however, the correlation between individual FRS dimensions and out-degree centrality varies considerably. Even though all correlations are positive, they are very weak for intersectorality and multilevel governance. Only transterritoriality shows a significant correlation, where close to half of all cases confirm our hypothesis. This uneven confidence in our hypothesis is partly a reflection of the two contrasting trajectories identified in Section 4.1. For instance, because one ERMI (Pyrenees) that follows the institution-building oriented trajectory scores relatively low on intersectorality, pronounced intersectorality in the other ERMIs of that trajectory (Alps and the Jura) fail to compensate for good intersectorality despite weak diffusion roles among ERMIs following the problem-oriented trajectory. Conversely, correlation between transterritoriality and diffusion centrality is evident at the level of the contrasting trajectories.

Third, our findings with respect to Hypothesis 2 only partially corroborate the claims by Klingler-Vidra and Schleifer (2014). On the one hand, because diffusion to the Southeast European and Caucasus ERMIs is dominated by the Carpathian ERMI as a single source, a single instrument (the Carpathian Convention), and more or less a single actor (UNEP), there is a relatively pronounced degree of convergence among the latter (i.e. precedence of intersectorality over transterritoriality, multilevel governance and degree of formalization and institutionalization). On the other hand, the same degree of convergence cannot be observed with respect to the Alpine ERMI as a single source of diffusion, where diffusion to all other ERMIs produced considerable divergence. Some of this latter divergence can be explained by the fact that the Alpine ERMI consists of multiple and diverse instruments, which emerged at different points in history and assumed different institutional forms: diffusion via working communities in the 1970s and 1980s, diffusion via the Alpine Convention since the 1990s, and diffusion via the Alpine Space Programme since the 2000s. In turn, this would confirm the suggestion by KlinglerVidra and Schleifer that chain diffusion and multiple-source diffusion undermines convergence.

\subsection{Hypothesis 3}

The third hypothesis posits a positive relationship between An ERMI's degree of formalization and institutionalization and its position and role in policy diffusion. This hypothesis is only partially confirmed. At the level of the three clusters identified in Section 4.1, we find that Cluster 1 ERMIs (Alps, Jura, Pyrenees) are the most institutionalized and primarily act as a source of diffusion with reference to Cluster 2 (Carpathians) and Cluster 3 (Balkan Mountains, Dinaric Arc, Caucasus). Similarly, the Cluster 2 ERMI is more institutionalized than Cluster 3 ERMIs and acts as a source for Cluster 3 ERMIs.

However, the hypothesis cannot be fully confirmed if we consider the situation at the level of individual ERMIs rather than at the cluster level. If the case of the Alpine Convention conforms to our expectation (it is simultaneously the most institutionalized ERMI and the main source of diffusion), the cases of the Pyrenees and the Jura show that long-institutionalized ERMIs do not necessarily play a central role in the diffusion process. It thus suggests that other factors such as size, position and role in the scientific networks or epistemic communities play an important role in the structuration of policy diffusion dynamics.

\section{Conclusion}

\subsection{Summary of the main results}

This article has demonstrated the relevance of the FRS approach for analyzing and typologizing European regional mountain initiatives. In this context, pairwise comparison proves to be a useful, if not exceedingly rigorous (see below) approach to comparing complex governance systems. As concerns the FRS concept itself, one critical remark nevertheless needs to be raised, namely the implicit notion that greater proximity to an ideal-type FRS augments regulatory capacity, which fails to integrate contextual dimensions linked to the emergence and operation of an FRS. Instead, transaction costs and policy benefits could mean that an ideal-type FRS is not necessarily the most efficient approach to solving wicked problems, yet it may be widely adopted because intersectoral, transterritorial multilevel governance approaches are considered the most appropriate for addressing wicked problems.

The article has also shown the existence of a positive correlation between the proximity of an ERMI to an FRS ideal type and its central role in the policy diffusion processes. It thus contributes to the literature on policy diffusion in two ways. First, it goes beyond the study of concrete practices and considers the spread of governance models. Second, it provides insights into diffusion between regions, rather than diffusion between individual countries or organizations.

\subsection{Research agenda for the future}

A first item on a future research agenda would be to improve the analytical method for implementing the ideal-type approach. One of the main challenges will thus be to overcome the limits of an indirect pairwise comparison approach, notably through the development of sets of clear and robust criteria for directly measuring the proximity/distance of each empirical ERMIs from the ideal type FRS; as noted above, this would entail switching from an ordinal to a interval scale. Such a refinement of the ideal-type "cube" approach could also be useful for improving confidence in the collinearity analysis.

At the same time, the analysis of policy diffusion patterns should seek to extend and deepen knowledge of the actors, mechanisms, channels, and temporality of diffusion. Therefore, the analysis should not be limited to the diffusion of policy designs and models, but also take into account, their implementation processes, outputs, and impacts in the different mountain ranges.

Finally, in order to strengthen the collinearity analysis, one should also increase the number of cases through the comparison with other mountain initiatives in the world and/or with other types of FRS initiatives such as coastal 
zones, metropolitan areas or water basins, where intersectorality, transterritoriality, and multilevel governance and explicit policy goals. Alternatively, the relationship between ideal-type FRS approximation and diffusion centrality could be examined in domestic, rather than transboundary contexts, where transterritoriality would primarily relate to intermunicipal or interprovincial coordination.

\section{Acknowledgments}

The authors would like to thank the anonymous reviewers for their constructive comments on the manuscript. The research presented in this paper was made possible by grants from the Swiss National Science Foundation (project "European Regional Mountain Initiatives: From Caucasus to Pyrenees", Nr. 137989; project "GLO-RETE: Globalization and re-territorialization of environmental initiatives in Central Europe: stakeholders, narratives, images", Nr. 125414) and the Swiss Network for International Studies (project "Mountlennium: Reaching Millennium Development Goals through Regional Mountain Governance").
Bourdieu, P., Chamboredon, J.-C., Passeron, J.-C., 1991. The Craft of Sociology: Epistemological Preliminaries. De Gruyter, Berlin.

Brenner, N., 2004. New State Spaces: Urban Governance and the Rescaling of Statehood. Oxford University Press, Oxford.

Busch, P.-O., Jörgens, H., Tews, K., 2005. The global diffusion of regulatory instruments: the making of a new international environmental regime. Ann. Am. Acad. Pol. Soc. Sci. 598, 146-167.

Carpathian Convention, 2003. Framework Convention on the Protection and Sustainable Development of the Carpathians, Adopted in May 2003 in Kyiv, Ukraine.

De Sousa, L., 2013. Understanding European cross-border cooperation: a framework for analysis. J. Eur. Integr. 35 (6) 669-687.

Debarbieux, B., Balsiger, J., Djordjevic, D., Gaberell, S., Rudaz, G., 2014. Scientific collectives in region-building processes.

Environ. Sci. Policy, http://dx.doi.org/10.1016/ j.envsci.2014.06.005.

Debarbieux, B., Rudaz, G., 2010. Les faiseurs de montagne. Centre National de la Recherche Scientifique (CNRS) Editions, Paris.

Debarbieux, B., Price, M., Balsiger, J., 2013. The institutionalization of European mountain regions. Reg. Stud., http://dx.doi.org/10.1080/00343404.2013.812784.

\begin{tabular}{|c|c|c|}
\hline Mountain range & Countries involved & Key initiatives \\
\hline Alps & $\begin{array}{l}\text { Austria, France, Germany, Italy Liechtenstein, Monaco, } \\
\text { Slovenia, Switzerland, European Union }\end{array}$ & $\begin{array}{l}\text { Working Community Arge Alp (1972); Working Community } \\
\text { Alpe-Adria (1978); Working Community Western Alps (1982); } \\
\text { Alpine Convention (1991), Alpine Space Programme (2000) }\end{array}$ \\
\hline Pyrenees & France, Spain, Andorra & Working Community for the Pyrenees (1983) \\
\hline Jura & France, Switzerland & Conférence Transjurassienne $(1985,2001)$ \\
\hline Carpathians & $\begin{array}{l}\text { Czech Republic, Hungary, Poland, Romania, Serbia, } \\
\text { Slovak Republic, Ukraine }\end{array}$ & Carpathian Convention (2003) \\
\hline Balkan Mountains & $\begin{array}{l}\text { Albania, Bosnia and Herzegovina, Bulgaria, Croatia, } \\
\text { Former Yugoslav Republic of Macedonia, Greece, } \\
\text { Montenegro, Serbia, }\end{array}$ & $\begin{array}{l}\text { Draft Framework Convention on the Protection and } \\
\text { Sustainable Development of the South East European } \\
\text { Mountain Region (2006) }\end{array}$ \\
\hline Dinaric Arc & $\begin{array}{l}\text { Albania, Bosnia and Herzegovina, Croatia, Montenegro, } \\
\text { Serbia, Slovenia, }\end{array}$ & $\begin{array}{l}\text { Resolution on the Protection and Sustainable Development } \\
\text { of the Dinaric Arc and Neighboring Regions (2011) }\end{array}$ \\
\hline Caucasus & $\begin{array}{l}\text { Armenia, Azerbaijan, Georgia, Iran, Russian Federation, } \\
\text { Turkey }\end{array}$ & Vaduz Ministerial Statement (2007) \\
\hline
\end{tabular}

\section{REFEREN C E S}

Alpine Convention, 1991. http://www.alpconv.org/en/ convention/framework/default.html.

Balsiger, J., 2009. The impact of ecoregional mobilization on mountain policies in the Swiss Alps and California's Sierra Nevada. J. Alp. Res. 97 (2) 39-59.

Balsiger, J., 2012. New environmental regionalism and sustainable development in the European Alps. Glob. Environ. Pol. 12 (3) 58-78.

Bandura, A., 1977. Social Learning Theory. Prentice Hall, Englewood Cliffs, NJ.

Börzel, T.A., Risse, T., 2012. From Europeanisation to diffusion: introduction. West Eur. Pol. 35, 1-19.
Dinaric Arc Resolution, 2011. Resolution on the Protection and Sustainable Development of the Dinaric Arc and Neighbouring Regions, Adopted at Brdo, Slovenia, on 9 March 2011.

Djordjevic, D., 2014. International agreements and regionbuilding in the mountains of south east Europe. Mt. Res. Dev. 34 (1) 4-12.

Djordjevic, D., Balsiger, J., 2012. A view from the mountains: national involvement in Southeast European regionalization. In: Proceedings of the Berlin Conferences on Human Dimensions of Global Environmental Change. Free University of Berlin, Berlin.

Dobbin, F., Simmons, B., Garrett, G., 2007. The global diffusion of public policies: social construction, coercion, competition, or learning? Annu. Rev. Sociol. 33, 449-472. 
Elkins, Z., Simmons, B., 2005. On waves, clusters, and diffusion: a conceptual framework. Ann. Am. Acad. Pol. Soc. Sci. 598, 33-51.

Euromontana, 2014. Balkan Desk Development Associations Balkan Mountain. In: http://www.euromontana.org/en/ project/past-projects/balkan-desk/(accessed 19.10.14).

Falkner, R., Gupta, A., 2009. The limits of regulatory convergence: globalization and GMO politics in the south. Int. Environ. Agreem. 9, 113-133.

Gaberell, S., 2013. Framing mountains for regional environmental cooperation: the case of the Carpathians. In: Balsiger, J., Uyar, A. (Eds.), Comparing Regional Environmental Governance in East Asia and Europe: Proceedings. Research Institute for Humanity and Nature, Kyoto, pp. 35-42.

Gaberell, S., 2014. L'écorégionalisation en action: la construction institutionnelle des Carpates. University of Geneva, Department of Geography and Environment. (Ph.D. thesis).

Gaberell, S., Debarbieux, B., 2014. Mapping regions, framing projects: a comparative analysis on the role of mapping in the region-building process of two European regions. Geoforum 52, 123-136.

Jouve, B., 2007. Le Political Rescaling pour théoriser l'Etat et la compétition territoriale en Europe. In: Faure, A., Leresche, J.-P., Muller, P., Nahrath, S. (Eds.), Action publique et changement d'échelle, les nouvelles focales du politique. L'Harmattan, Paris.

Klingler-Vidra, R., Schleifer, P., 2014. Convergence more or less: why do practices vary as they diffuse? Int. Stud. Rev. 16, 264-274.

Levin, K., Cashore, B., Bernstein, S., Auld, G., 2012. Overcoming the tragedy of super wicked problems: constraining our future selves to ameliorate global climate change. Policy Sci. 45, 123-152.

Lewis, G., Benson, P., 2014. The evolution and current state of public affairs in Hungary. J. Public Aff. 14 (1) 67-75.

Radaelli, C.M., 2005. Diffusion without convergence: how political context shapes the adoption of regulatory impact assessment. J. Eur. Public Policy 12, 924-943.

Rittel, H., Webber, M., 1973. Dilemmas in a general theory of planning. Policy Sci. 4, 155-169.

Saaty, T.L., 1980. The Analytic Hierarchy Process. McGraw-Hill, New York.

Strang, D., Soule, S.A., 1998. Diffusion in organizations and social movements: from hybrid corn to poison pills. Annu. Rev. Sociol. 24, 265-290.

Varone, F., Nahrath, S., Aubin, D., Gerber, J.-D., 2013. Functional regulatory spaces. Policy Sci. 46 (4) 311-333.

Wasserman, S., Faust, K., 1994. Social Network Analysis: Methods and Applications. Cambridge University Press, Cambridge.

Weber, M., 1997 [1903-1917]. The Methodology of the Social Sciences. Free Press, New York. 